\title{
Adsorption - Desorption of Trimethoprim Antibiotic Drug from Aqueous Solution by Two Different Natural Occurring Adsorbents
}

\author{
Reem. A. Al-Bayati \\ Chemistry Department /College of Science /AL-Mustansirya \\ University, Baghdad, IRAQ \\ E-mail: Dr.Reem2000@yahoo.com \\ Athraa.S. Ahmed \\ Chemistry Department /College of Science /AL-Mustansirya \\ University, Baghdad, IRAQ \\ E-mail: Athraa.Salman@yahoo.com
}

Received: January 27, 2011 Accepted: February 14, 2011 doi:10.5539/ijc.v3n3p21

\begin{abstract}
In this study, removal of one of antibiotic drags from aqueous solution by adsorption was investigated. For this purpose, trimethoprim was used as one of antibiotic drug model. The cellulose acetate polymer and attapuligate clay were used as adsorbents. The equilibrium adsorption contact time were investigated for both cellulose acetate and attapuligate. Adsorption isotherms of trimethoprim on the two surfaces used from aqueous solution were determined. These adsorption isotherms were seen to be consistent with Freundlich adsorption isotherm. $\mathrm{k}$ and $\mathrm{n}$ constants were determined from Freundlich linear equation. The effect of initial drug concentration, temperature, $\mathrm{pH}$ of solution, ionic strength and desorption of the drug from the two adsorbents were studied.
\end{abstract}

Keywords: Trimethoprim, Adsorption, Attapuligate, Cellulose acetate, Adsorption from aqueous solution, Adsorption isotherm, Desorption

\section{Introduction}

Drug poisoning has been defined as a condition produced by any substance which when swallowed, inhaled, injected, or absorbed precutaneously is capable of causing death, injury, toxic reactions (1). On of perspective methods for emergency treatment of accidental poisoning by drug is adsorption $(2,3)$. In cases where no specific antidotes exist, prevention of further adsorption of a drug from the oral route is by use of oral adsorbents. Using adsorption method, the adsorbents have to answer to number of requirements, to be active, stable, accessible, cheap, and the most important is that the exchange ions should be harmless. The use of natural adsorbents (attapuligate clay and cellulose acetate polymer) in the prevention of further adsorption of drug, are recognized in clinical practice. The safety, and the high specific surface have been accepted for a long time, and they account (the clay and the polymer used) for most of the current uses of these two adsorbents (4-6).

Attapuligate clay may be used as adsorbent for some alkaloids, bacteria, dyes, odors and viruses. It is stated to be non-toxic and used as additives to the tablets and in the greaseless ointments (7).

On the other hands, cellulose acetate polymer (CA) has been employed in the technology of sustained release coating of solid dosage forms because of its properties (8). Marc Landenberg et al., (9) studied the comparison of the adsorption of several drugs to typical filter materials, and one of them was cellulose acetate polymer.

Trimethoprim is antibiotic that fights bacteria in the body. It is available and active as oral dosage forms and it is used to treat bladder infection caused by certain bacteria. Also, trimethoprim is active against a range of Gram-positive and Gram-negative bacteria, including aerobic Gram-positive coccid and somo rods, and it is also active Chlamydia, coccidian, toxoplasma and is pneumocyst cardinal(10). Trimethoprim has a good absorption from the gut. Peak levels about one to four hours after oral administration, in ruminants, orally administered trimethoprim is trapped in the rumen-reticulum and partially degraded.

The most common expected symptoms with overdose and acute toxicity of trimethoprim are gastrointestinal 
distress (nausea, vomiting, and diarrhea), central nervous system toxicity (depression, headache, and confusion), facial swelling, depression of bone marrow, and increase serum amino transferees (11). Oral overdose may be treated by empting the stomach (normal protocols such as resorption of trimethoprim in the gut and gastrointestinal tract or administration of adsorbents (12). This study reports the experimental results for adsorption and desorption of trimethoprim drug. The adsorption data are tested for a number of isotherm equations. Moreover, the current study has been to visualize the pattern of adsorption of this drug on the two different adsorbents to various situations such as ionic strength, $\mathrm{PH}$, temperature, contact time and desorption.

\section{Experimental}

\subsection{Materials}

The drug employed in this study (Trimethoprim) was obtained from (the state Enterprise for the drugs Industries and Medical Appliances) in Samarra- Iraq (SDI). Sharp melting point was noticed for this drug between $\left(199{ }^{\circ} \mathrm{C}\right.$ $-203{ }^{\circ} \mathrm{C}$ ) (structure 1), and the molecular weight is equal to $290.3 \mathrm{~g} / \mathrm{mol}$, the maximum absorption $\lambda_{\max }=280$ nm.(13).

The attapuligate clay employed in this study was obtained from (The general company for Geological survey and mining), Baghdad. The clay in powder form was washed several times with excessive amounts of distilled water and then dried at $\left(160{ }^{\circ} \mathrm{C}\right)$ in an oven (Hot Air Oven, Yamato DP61, Japan) for three hours and then kept in airtight containers. The cellulose acetate polymer employed in this study was obtained from (BDH Chemicals Ltd., UK). The two adsorbents used in this work was then ground and sieved (Electrical sieve, Retsoh Gmb \& Co.), KG, Germany) by using a test sieve. (Retsoh Gmb \& Co. KG, Germany) sieve. The particle size of $125 \mu \mathrm{m}$ was used for both two adsorbents in the experiments of this research.

\subsection{Method}

The method of this paper is organized as follows. Section I contains the determination of degree of substitution of cellulose acetate. In section II we briefly review the adsorption-desorption systems of trimethoprim drug on the two natural accruing surfaces.

\section{Section I}

Determination of degree of substitution of cellulose acetate polymer.

The degree of substitution of (CA) was determined from the relation between acetic acid percentage (acetyl group) and degree of substitution which can be calculated by using the following equation (1(14)):

$$
\frac{162 \times \mathrm{AC} \%}{100 \mathrm{~W}-\mathrm{W}_{1} \mathrm{AC} \%}
$$

D.S: degree of substitution.

W: formula weight for the substituted group (60 for acetic acid, 43 for acetyl).

W1: the increasing in formula weight for production cellulose from the addition of a substituted group on one enhydroglucose which is equal to 162 .

AC: the percentage of acetic acid or acetyl group.

The percentage of acetic acid or acetyl group (AC\%) was determined practically by using Eberstadt method (15)

\section{Section II}

Adsorption - desorption experiments of trimethoprim drug on two surfaces, used.

Adsorption experiments were carried out by shaking $(0.25 \mathrm{~g})$ of both of the adsorbents used in separate form with $(12.5 \mathrm{~mL})$ from aqueous solution of trimethoprim drug of desired concentration at various temperatures (23, $\left.37.5,43{ }^{\circ} \mathrm{C}\right)$, PHs (natural $\mathrm{PH}$ and acidic $\mathrm{PH}=1.2$ ), and ionic strengths $(0.03$ and $0.06 \mathrm{M} \mathrm{NaCl}$ solutions in water) for 2 hours and 2.5 hours (the required time for attapuligate clay and cellulose acetate polymer respectively to reach the equilibrium concentration). A thermo stated shaker bath (BS.II digital, JEI. TECH, Korea, (20-185) $\operatorname{rpm}\left(0-120^{\circ} \mathrm{C}\right)$, was used to keep the temperature constant.

The initial concentration of drug solution, $\mathrm{Co}$, were in the range of $\left(9 \times 10^{-5}-3.8 \times 10^{-4} \mathrm{~mol} \cdot \mathrm{L}^{-1}\right)$. All adsorption experiments were performed at $37.5^{\circ} \mathrm{C}$ and neutral $\mathrm{PH}$ expects those in which the effects of temperature and $\mathrm{PH}$ of the solution were investigated. The $\mathrm{PH}$ of the solution was adjusted with $\mathrm{HCl}$ solution by using (HM-73, TDA Electronics Ltd.) PH meter. At the end of the adsorption period, solution was filtered by using double filter papers (Whatman No. 42, Germany), and then the concentration of the residual drug, Ce, was determined with the aid of ultraviolet visible recording spectrophotometer (100 conc./VARIAN, USA). The adsorbed amounts of 
drug were calculated from the concentrations in solutions before and after adsorption according to equation (2):

$$
\mathrm{Qe}=(\mathrm{Co}-\mathrm{Ce}) \frac{\mathrm{V}}{\mathrm{W}}
$$

Where Co and Ce are the initial and equilibrium liquid - phase concentrations of drug solution (mol.L-1), respectively, Qe is equilibrium drug concentration on adsorbent $\left(\mathrm{mol} \cdot \mathrm{g}^{-1}\right), \mathrm{V}$ is the volume of drug solution (L), and $\mathrm{W}$ is the mass of adsorbent sample used (g). For a desorption experiments, the remainder of the supernatant of the sorption flasks after setting was removed and $(12.5 \mathrm{~mL})$ portions of eluent was added to the sorbent residue in each flask. The mixture was allowed to equilibrate for one hour in the shaker and the suspensions were centrifuged for 15 minutes (JANETZKI.T 130). The concentration of the drug desorbed was determined in the supernatant $(16,17)$.

$$
\text { The amount desorbed }(\mathrm{mg} / \mathrm{g})=\frac{\mathrm{Ce} . \mathrm{V}}{\mathrm{W}}
$$

Where Ce is the concentration of drug desorbed at equilibrium $\left(\mathrm{mg} \cdot \mathrm{L}^{-1}\right), \mathrm{V}$ is the volume of eluent $(\mathrm{L})$, and $\mathrm{W}$ represents the weight of adsorbent $(\mathrm{g})$.

The percent of desorption was obtained from the following equation

$$
\text { Percent desorption }=\frac{\text { Amount of drug desorbed }}{\text { Amount of drug adsorbed }}
$$

\section{Results and discussion:}

\subsection{The Specification of Cellulose Acetate}

From the test done to estimate the specification of cellulose acetate that has been used in this work, we can get:

1-The percentage of acetic acid $(\mathrm{AC} \%)=52.8 \%$.

2- The percentage of acetate $(\mathrm{AC} \%)=37.8 \%$.

3- The degree of substitution (D.S) $=2.26$

The results above indicate that the cellulose acetate which has been used in this study was a secondary cellulose acetate.

\subsection{Adsorption isotherm of aqueous drug solution}

It is generally possible to express the results of experimental sorption measurements in the form of equilibrium sorption isotherms. Figure (2) displays the isotherms of adsorption related to trimethoprim drug from aqueous solution on cellulose acetate and attapuligate surfaces. It was seen that these isotherms fitted the Freundlich adsorption isotherm. Experimental data was also applied to the Langmuir adsorption isotherm (equation 5), but the linear state of the Langmuir adsorption isotherm was not obtained. This consistency is seen in the Freundlich linear adsorption isotherm drawn according to equation (6) (18), figure (3).

$$
\begin{gathered}
\mathrm{Ce} / \mathrm{Xm}=1 / \mathrm{ab}+(1 / \mathrm{a}) \mathrm{Ce} \\
\mathrm{Xm}=\mathrm{KCe}^{1 / \mathrm{n}}
\end{gathered}
$$

Where $(\mathrm{Ce})$ is the equilibrium concentration of drug in solution $(\mathrm{mg} / \mathrm{L}),(\mathrm{Xm})$ is the amount of drug sorbed per unit of sorbent $(\mathrm{mg} / \mathrm{g})$, (a) is a constant related to the area occupied by monolayer of sorbent, reflecting the sorption capacity $(\mathrm{mg} / \mathrm{g}),(\mathrm{b})$ is a dried measure for the intensity of the sorption process $(\mathrm{L} / \mathrm{mg}),(\mathrm{K})$ and $(\mathrm{n})$ constants peculiar to adsorbent and adsorbate were determined from the intercept and slope of Freundlich adsorption isotherm.

The $(\mathrm{K})$ constant is concerned with the ability of the adsorbent to adsorb and the (n)-constant is concerned with tendency of the adsorbate to be adsorbed. In order to prove the applicability of Freundlich isotherm as shown by the linear relationships of logarithmic forms of Qe and Ce, figure (3). The R2 values (goodness of fit) computed by linear regression for the two types of isotherms are presented in table (1) for the two sorbents. 
The data in table (1) indicate that the best fit isotherm is a function of the sorbent and sorbate considered each time (Kindly see the related tables and figures in the pages after References).

As can be seen in table (2), the (n) constants of the adsorbent surfaces change in the order of cellulose acetate polymeric surface $>$ attapuligate clay surface. It is seen that the (n) constants obtained fit the Irving - Williams series because the stable system formed increases the ability of the adsorbate to be adsorbed and causes the $\mathrm{n}-$ constant to be high. This is compatible with our experimental results.

\subsection{Effect of ionic strength}

The effect of ionic strength on adsorption uptake of trimethoprim drug on the two adsorbent surfaces was studied at variable salt concentration $(0.03 \mathrm{M}$ and $0.06 \mathrm{M})$ of sodium chloride. As can be seen in figures $(4,5)$ the increasing ionic strength in the solution causes a decrease in the adsorption of trimethoprim drug on to both clay and polymeric surfaces at the neutral $\mathrm{PH}$ and $37.5{ }^{\circ} \mathrm{C}$. This behavior may be due to the inhibition effect of salt used on adsorption extent. Thus, the $\left(\mathrm{Na}^{+}\right),\left(\mathrm{Cl}^{-}\right)$ions will compete drug molecules for the active sites which could be found on the surface. Moreover, the attraction between these ions and the surface is grater than that attraction between the drug molecules and the surface, therefore, the electrostatic attraction will decrease between the adsorbent and the adsorbate and that leads to decrease in the adsorption extent (19). These results agreed with the earlier investigations $(20,21)$ which concerning the effect of normal saline on drug adsorption.

\subsection{Effect of PH}

The adsorption of drug from aqueous solution is highly dependent on the $\mathrm{PH}$ of solution which affects the surface charge of the adsorbent, and the degree of ionization and speciation of the adsorbate species (22).

$0.1 \mathrm{M}$ hydrochloric acid was used to mimic the acidity of the stomach where drug that are taken orally are retained for some time prior to absorption from the gastrointestinal tract (23).

Shaking at $37.5{ }^{\circ} \mathrm{C}$ was to mimic the gastrointestinal motility and body temperature. Figure $(6,7)$ demonstrates the influence of $\mathrm{PH}$ on the adsorption uptake on fixed drug concentrations by the two adsorbents used at $\left(37.5{ }^{\circ} \mathrm{C}\right)$. The adsorption extent of trimethoprim on attapuligate clay surface in aqueous solution of hydrochloric acid at $\mathrm{PH}=1.2$ was grater than the corresponding adsorption extent using distilled water as a solvent. The attraction between the surface and the drug used at low PH value may be specific and stronger than the attraction between the solvent - solute leading to an increase in the quantity adsorbed (24).

On the other hand, the adsorption of the same drug and the same conditions on cellulose acetate polymeric surface showed a different behavior, an increase in adsorption quantities of the drug on this surface with increasing $\mathrm{PH}$ values. At low $\mathrm{PH}$, a competition exerted by the hydronium ions is expected to cause a significant reduction in adsorption of the drug. In addition, the solubility of the adsorbates (drug) may be affected by the change of the $\mathrm{PH}$ value (from acidic to neutral) causing an increase in adsorption affinity towards the surface. Moreover, the increase in adsorption uptake of the drug with increasing PH of solution could be attributed to the possible changes in properties of the surface (24). This result agreed with the earlier investigation (25) which concerning the effect of $\mathrm{PH}$ on drugs adsorption using cellulose acetate as an adsorbent surface.

\subsection{Effect of Temperature and Thermodynamic Parameters}

The adsorption of trimethoprim drug on attapuligate clay surface and cellulose acetate polymeric surface at three different temperatures has been carried out and shown in figures (8) and (9). Variable temperatures will help in evaluating the basic thermo dynamical functions $(\Delta \mathrm{H}, \Delta \mathrm{G}, \Delta \mathrm{S})$ of the adsorption process.

Adsorption of trimethoprim on the two surfaces used in this work decreases with increasing temperature. These results agree with the general principles of the adsorption process (26).

To calculate the heat of adsorption $(\Delta \mathrm{H})$ we used the following equation:

$$
\ln \mathrm{Xm}=(-\Delta \mathrm{H} / \mathrm{RT})+\text { Constant }
$$

Where $(\mathrm{Xm})$ is the maximum uptake of adsorption at a certain value of equilibrium concentration $(\mathrm{Ce})$ that was fixed for all temperatures of the study (27). The change in free energy $(\Delta \mathrm{G})$ could be determined from the equation:

$$
\Delta \mathrm{G}=-\mathrm{RT} \ln \mathrm{K}
$$

Where $\mathrm{R}$ is the gas constant $\left(8.314 \mathrm{~J} \cdot \mathrm{mol}^{-1} \cdot \mathrm{deg}^{-1}\right),(\mathrm{T})$ is the absolute temperature, and $(\mathrm{K})$ is the equilibrium constant for the adsorption at a certain value of equilibrium (28). The change in entropies $(\Delta \mathrm{S})$ was calculated from Gibbs equation (29).

$$
\Delta \mathrm{G}=\Delta \mathrm{H}-\mathrm{T} \Delta \mathrm{S}
$$


Table (3) shows the basic thermodynamic values of adsorption of the drug on two surfaces used in this study. Thermodynamic quantities showed exothermic heat of adsorption accompanied with a decrease in entropies suggesting an increase in orderliness' of the system, in other words because of the fact that of dissolved solutes. This is the normal consequence of the physical adsorption phenomenon, which takes phase through electrostatic interactions (30). The change in free energy $(\Delta G)$ of the adsorption process was found to possess negative values indicating a spontaneous adsorption process.

\subsection{Desorption of the drug from the adsorbents surfaces}

The desorption is similar to adsorption process depending mainly on solution temperature, concentration of adsorptive, the condition of adsorptive and on the condition of the adsorbent surface. The possibility of desorption of the drug model (trimethoprim) from the two surfaces used (attapuligate clay and cellulose acetate polymer) was investigated using distilled water as an eluent to simulate in vivo conditions. The extent of drug desorption from the two surfaces at $\left(37.5^{\circ} \mathrm{C}\right)$ increase as the concentration of the drug in its solution increase as its shown in figures (10), (11). This is due to the strong interaction of adsorbate - adsorbent system and the heterogeneity of the surface, which indicates the difficulty of the drug release at low concentrations.

The percent desorption after one washing procedure with distilled water was also determined. The results are summarized in table (4) by the amount of drug released in one elution step.

The release studies show the lowest percentage amount of drug desorbed from attapuligate clay surface (11.03) followed by cellulose acetate polymeric surface (27.89). The low desorption percent obtained with attapuligate may be interpreted by type of forces acting between the surface and the drug molecules. In addition to caution of exchange mechanism, adsorption of the drug on the two adsorbents surfaces used is through to take place as a result of other types of interaction.

\section{Conclusion}

1). The adsorption of trimethoprim antibiotic drug from aqueous solutions on both attapuligate and cellulose acetate surfaces is a function of initial drug concentration, temperature and contact time.

2). The contact time for the maximum adsorption of the drug on attapuligate clay surface required is two hours and for cellulose acetate polymeric surface was about two and a half hours.

3). Although the two surfaces used in this study can adsorb trimethoprim antibiotic drug, but the most selective surface observed was attapuligate which appeared to posses' highly active adsorption capacity. This conclusion could be applied in medicine for the treatment of poisoning by the above drug.

4). Adsorption isotherm of trimethoprim on both surfaces used obeyed Freundlich isotherm. This result indicated the surface heterogeneity leading to different adsorption forces from site to site and different affinities toward drug molecules.

5). Adsorption capacities were found to decrease as the ionic strength increased. Additions of two different concentrations of sodium chloride caused a decreased in the ionic strength and hence decreased the adsorption capacities.

6). Adsorption extent of trimethoprim at $\mathrm{PH}=1.2$ on attapuligate clay surface was found to increase as compared with the neutral medium. The adsorption of the same drug on cellulose acetate polymeric surface was decreased at $\mathrm{PH}=1.2$. These results were interpreted in terms of the effect of $\mathrm{PH}$ on the nature of surface, solvent and solute species.

7). The a desorbed quantities of trimethoprim on the two surfaces used decreased with increasing the temperature.

8). The Desorption abilities (the amount desorbed) of trimethoprim drug from both surfaces at $37.5{ }^{\circ} \mathrm{C}$ follow the order:

Cellulose acetate $>$ attapuligate.

9) Finally, it can be concluded that it is necessary for various adsorbents in nature to be tested because of their different surface properties in the determination of optimum conditions in terms of adsorbents.

\section{References}

A. Goth. (1984). Medical pharmacology, 11th ed., the C.V. Mosby company, Toronto pp. 721-722.

A., Adamson. (1984). Physical chemistry of Surfaces, 4th ed. Wiley Interscience Pub., pp.: $369-398$.

A.Akintonwa, and O.E. Orisakwe. (1990). Arch. Int. Pharmcodyn. Ther., 304, pp. 290-295. 
AL-Bayati Reem Adham. (2007). Adsorption - sorption systems of some drugs on naturally occurring polymers and bentonite cay PhD Thesis, AL-Mustansirya University.

Annual book of ASIM Standards. (1988). Vol. 15.04, D871 -72.

D.G. Hollander. (1980). J. Chem. Soc. Faraday Trans., 76, 386.

D.L. Sorby. (1965). Effect of adsorbents on drug absorption, J. Pharmaceutical Society, 54(5), pp. $677-683$.

DC. Bean, DM.Livermore, I.papa, L M., Hail. (2005). Resistance among Escherichia eoli to sulphonamides and other antimicrobials now little use in man. J. Antimicrobchemother, 56(5):pp. 962-4, November.

Debra Bourne MA VetMB, PhD. (2004). MRCVS Wildlife Information Network, the Royal Veterinary College, London, Document in November.

E.Ott, H.M. Spurlin, and M.W. Grafflin. (1955). Cellulose and Cellulose Derivatives., Part III, interscience, New York.

E.Voudrias, K.Fytianos and E.Bozani. (2002). Sorption - Desorption Isotherms of Dyes from Aqueous Solution and Wastewaters with Different sorbent Materials. The Int.J., Vol.4, No. 1, pp. 75 - 83.

G.M. Barrow. (1973). Physical Chemistry, 3rd. Mc Graw Hill, Japan, pp. 708 and 716.

Gracia Vita-Garcia DVM, Msc. (2006). MRCVS Wildlife Information Network, the Royal Veterinary College, London, August.

G-Van-Savage, and CT-Rhodes. (1995). sustained Release Coating of Solid Dosage Forms: historical review, Drug - Development - and Industrial - Pharmacy, 21 (1), PP. 93-118.

H.A. Elliott, and C.P. Huong. (1981). Adsorption Characteristics of some Cu(II) complexes on alumino silicates". Water Res., 15, 849.

Irish Medicines Board, April. (2004).

J.J. Kipling. (1965). Adsorption From Solution Of Non - Electrolytes, Academic Press. London, pp. 3,101 - 168, $257-259$.

J.Osich, and I.L.Copper. (1982). Adsorption, John Wiley and sons, Newyork, P. 126.

K.E. Nell, W.S.Hou. Gounaris. (1992). Adsorption Technology For Air and Water Pollution Control Lewis Publishers, Inc., USA.

Kirk - Othmer. (1964). Encyclopedia of Chemical Technology, 2nded., Vol.4, 632 - 636.

Marc Linden berg, Cornelia Wiegand, and B. Dressman Jennifer. (2005). Comparison of adsorption of Several Drugs to Typical Filter Materials", Dissolution Technologies, pp. 22-25, Feb.

Martindale. (1982). The Extra Pharmacopoeia, 28thed; Royal Pharmaceutical Society, London, p. 77.

Onyekweli Anthony, O Usifoh Cyril and D Zuofa Jessica et al. (2003). Adsorptive property of kaolin in some drug formulations, Tropical Journal of Pharmaceutical Research, June; 2(1), 155 - 159.

R.H.S. Rebertson. (1957). Chem., Ind.S, 1492.

R.H.S. Rebertson. (1973). Silicates, Ind. 38, 33.

T. Tsuchiya, and G. Levy. (1972). J. pharmaceutical Society, 61(4), pp. 586 - 589.

T.W.Weber and R.K. (1974). Chkrauorti, A.I.Ch.E.J., Vol.20, p. 228.

Terada, et al. (1994). Tokushima J. Exp. Med., 41(1-12), pp.: 31-40.

W.H. Jons, and T.R. Bates. (1972). J. Pharmaceutical Society, 61(5), pp. 730.734.

WF Von. (1983). otting men, recent research in emergency of accidental poisoning. In: A guide of clinical diagnosis and treatment, Philadelphia WB Sandors Company 400. 
Table 1. Goodness of fit of the Freundlich and Langmuir isotherm to the sorption experimental data. Values corresponding to best fit isotherm

\begin{tabular}{|l|c|c|}
\hline \multicolumn{1}{|c|}{ Adsorbent } & Freundlich isotherm & Langmuir isotherm \\
\hline Cellulose acetate & 0.931 & 0.810 \\
\hline Attapuligate & 0.949 & 0.097 \\
\hline
\end{tabular}

Table 2. Freundlich constants related to the adsorption of the drug from aqueous solution by Cellulose acetate and attapuligate

\begin{tabular}{|l|c|c|}
\hline \multicolumn{1}{|c|}{ Adsorbent } & $\mathrm{K}$ & $\mathrm{n}$ \\
\hline Cellulose acetate & 3.859 & 2.067 \\
\hline Attapuligate & 0.144 & 1.105 \\
\hline
\end{tabular}

Table 3. calculated thermodynamic parameters of trimethoprim adsorption on the adsorbent surfaces at $37.5{ }^{\circ} \mathrm{C}$

\begin{tabular}{|l|c|c|c|}
\hline \multicolumn{1}{|c|}{ Adsorbents } & $\Delta \mathrm{H} \mathrm{KJ} \cdot \mathrm{mol}^{-1}$ & $\Delta \mathrm{G} \mathrm{KJ} \cdot \mathrm{mol}^{-1}$ & $\Delta \mathrm{S} \mathrm{J} \cdot \mathrm{mol}^{-1} \mathrm{~K}^{-1}$ \\
\hline Attapuligate & -105.45 & -0.64 & -337.55 \\
\hline Cellulose acetate & -30.77 & -0.10 & -98.79 \\
\hline
\end{tabular}

Table 4. Percent desorption of Trimethoprim from the two surfaces used with distilled water as an eluent at $\left(37.5^{\circ} \mathrm{C}\right)$

\begin{tabular}{|c|c|c|c|}
\hline Adsorbent & Elution No. & Amount desorbed mg/g & Percent Desorption \\
\hline Attapuligate & 1 & 34.38 & 11.03 \\
\hline Cellulose acetate & 1 & 78.25 & 27.89 \\
\hline
\end{tabular}<smiles>COc1cc(Cc2cnc(N)nc2N)cc(C)c1OC</smiles>

\section{OMe}

Figure 1. The Trimethoprim structure 




Figure 2. Adsorption isotherm related to drug from aqueous solution on cellulose acetate and attapulgite

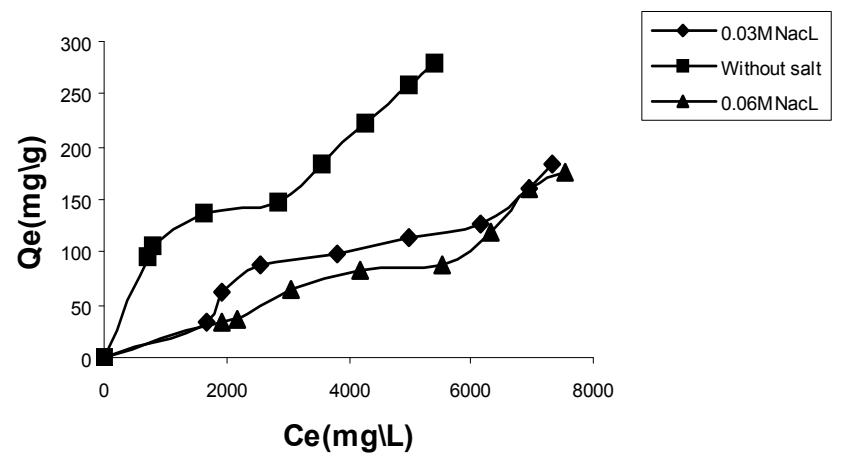

Figure 3. Freundlich linear isotherm related to adsorption of drug from aqueous solution on cellulose acetate and attapuligate

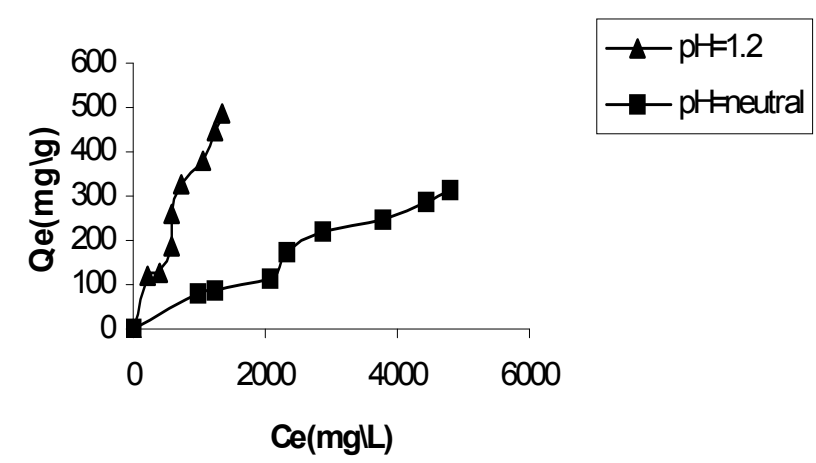

Figure 4. The effect of ionic strength on the adsorption of trimethoprim on cellulose acetate surface 

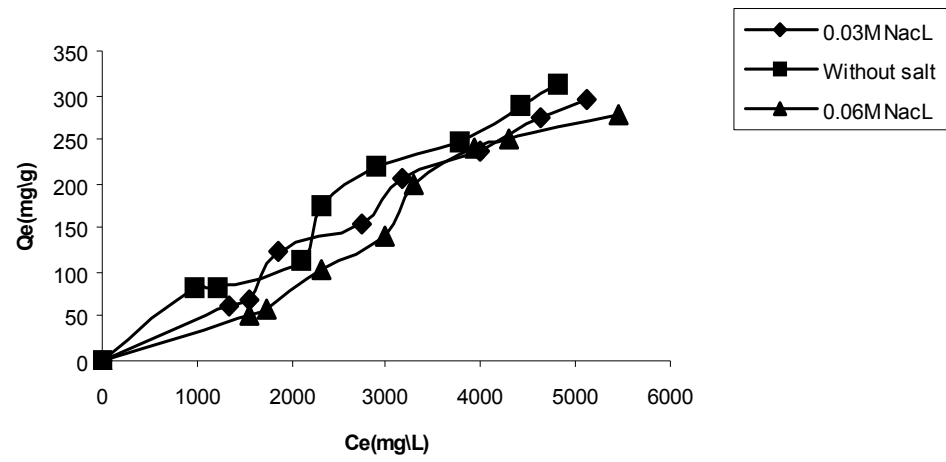

Figure 5. The effect of ionic strength on the adsorption of trimethoprim on attapulgite surface


Figure 6. The effect of $\mathrm{PH}$ on the adsorption of trimethoprim on attapuligate clay surface

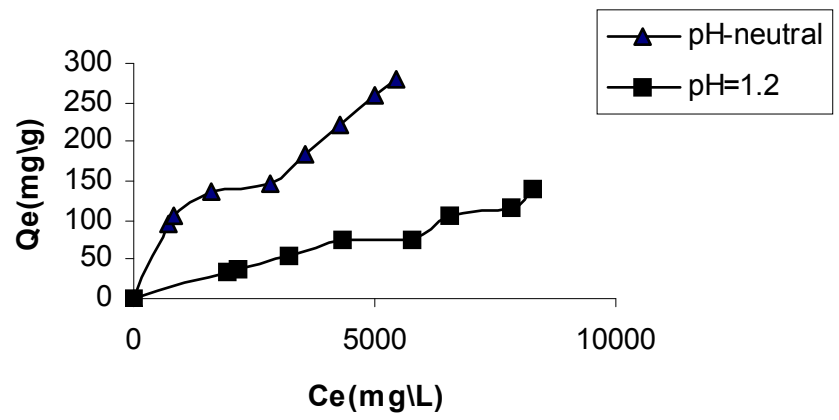

Figure 7. The effect of $\mathrm{PH}$ on the adsorption of trimethoprim on cellulose acetate polymeric surface
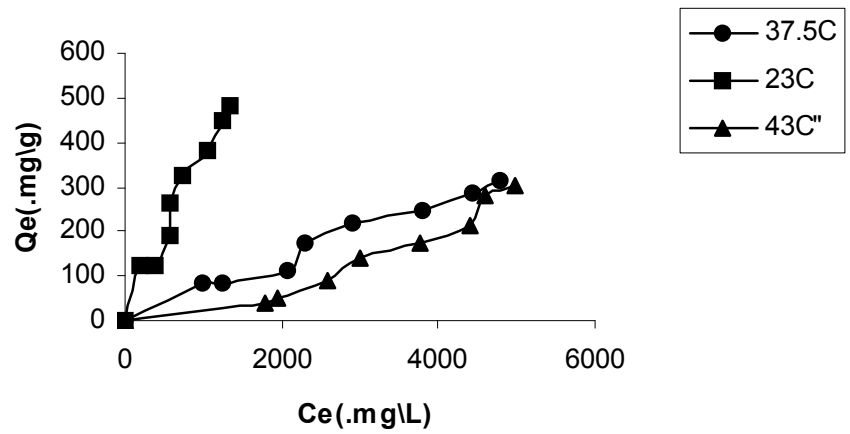

Figure 8. Adsorption isotherms of the drug on attapulgite at different temperatures 


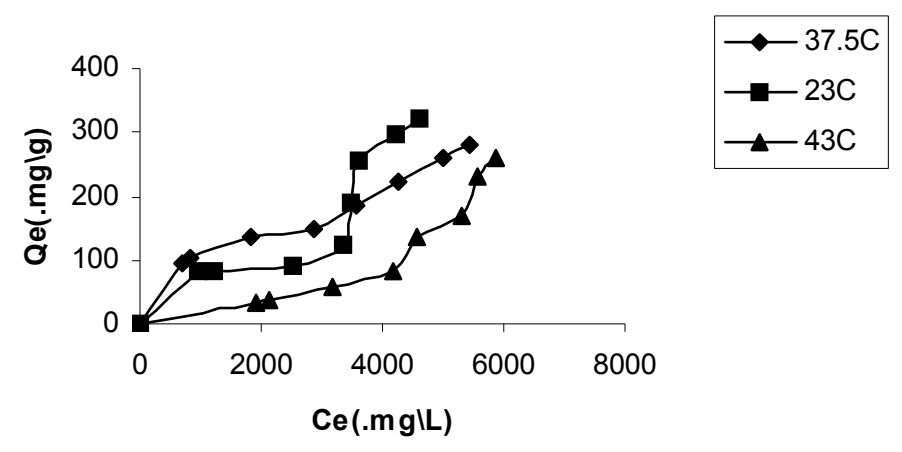

Figure 9. Adsorption isotherms of the drug on cellulose acetate at different temperatures

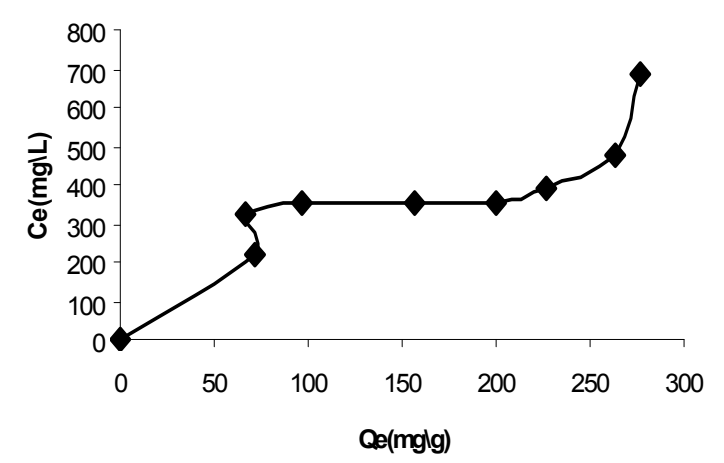

Figure 10. Desorption isotherm of trimethoprim drug from attapulgite clay surface by distilled water at $\left(37.5^{\circ} \mathrm{C}\right)$

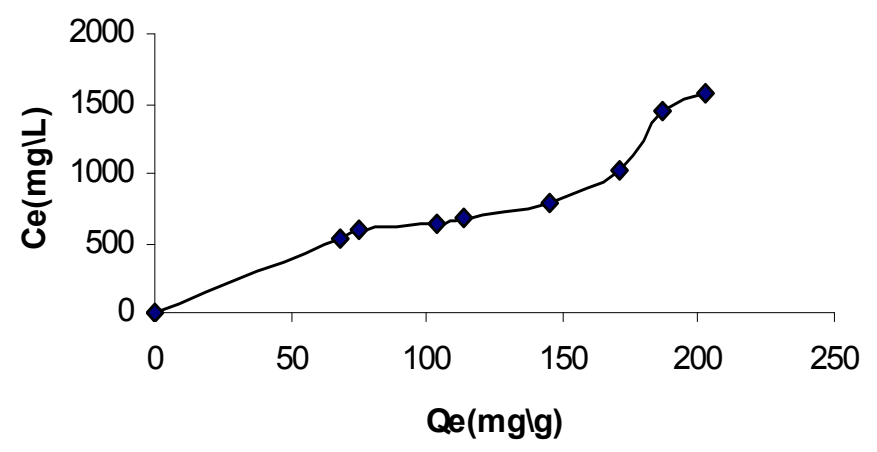

Figure 11. Desorption isotherm of trimethoprim drug from cellulose acetate polymeric surface by distilled water at $\left(37.5{ }^{\circ} \mathrm{C}\right)$ 